\title{
Increased risk of iodine deficiency with vegetarian nutrition
}

\author{
Thomas Remer*, Annette Neubert and Friedrich Manz \\ Research Institute of Child Nutrition, Heinstück 11, 44225 Dortmund, Germany \\ (Received 4 June 1998 - Revised 20 July 1998 -Accepted 5 August 1998)
}

\begin{abstract}
Observational studies primarily based on diet questionnaires or food records have reported that vegetarians can have a very low I intake. However, analytically ascertained data on the possible degree of I deficiency with this form of diet is lacking. Six healthy adult volunteers participated in the present controlled experimental diet study carried out in four separate $5 \mathrm{~d}$ diet periods. The study diets, normal, protein-rich, lactovegetarian, and repeat of the initial normal diet, were almost isoenergetic and contained no fish, sea food, iodized salt or processed foods fortified with I. During the last $48 \mathrm{~h}$ of each diet period two $24 \mathrm{~h}$ urine samples were obtained from each subject. I analyses were performed in the urine samples and in representative samples taken from all ingested diets. Urinary I excretion was significantly lower with the lactovegetarian diet (36.6 (SD 8.8) $\mu \mathrm{g} / \mathrm{d}$ ) than with the normal and the protein-rich diets (50.2 (SD 14.0) and 61.0 (SD 8.0) $\mu \mathrm{g} / \mathrm{d}$ respectively). Accordingly, a markedly reduced I intake was confirmed analytically for the lactovegetarian diet $(15.6 \mu \mathrm{g} / \mathrm{d} v .35 .2$ and $44.5 \mu \mathrm{g} / \mathrm{d}$ respectively). Our results provide experimental confirmation of literature findings indicating that I supply is higher with non-vegetarian than with vegetarian diets. Specifically, the extremely low intake and urinary output of I as analytically determined for one exemplary vegetarian diet, demonstrate that dietary I may be limiting when strict forms of vegetarian dietary practices (no iodized salt, no I supplements) are followed. The present study is, therefore, the first diet-experiment-based pointer to the potential danger of I deficiency disorders due to strict forms of vegetarian nutrition, especially when fruits and vegetables grown in soils with low I levels are ingested.
\end{abstract}

Iodine: Vegetarians: Micronutrients

Elimination of I deficiency is a global health priority (Maberly et al. 1994). More than one billion people worldwide consume inadequate daily amounts of I (International Council for Control of Iodine Deficiency Disorders, 1997) and are at risk of I deficiency disorders. Apart from enlargement of the thyroid (goitre) a wide spectrum of mental, psychomotor and growth abnormalities (Delange, 1994) as well as increased infant mortality (Cobra et al. 1997; DeLong et al. 1997) can result from I deficiency.

In industrialized countries with markedly less I deficiency than in developing countries, such health risks make it necessary to identify, particularly, those groups of people who still are at increased risk of I deficiency disorders despite universal access to iodized foods.

Literature findings indicate that vegans not consuming I supplements, seaweed and/or related products have inadequate intakes of dietary I (Draper et al. 1993; Rauma et al. 1994; Lightowler \& Davies, 1996). In many countries the I content of plant foods is very low due to an extremely low I concentration in the soil. On the other hand animal products such as eggs, cheese, milk, meat, fish, and poultry are important contributors to total I intake (Park et al. 1981).
In industrialized countries most animal feeds are supplemented with I.

However, reliable analytical data directly comparing the I status of subjects on vegetarian and non-vegetarian diets have hitherto been lacking. To address this issue directly, both dietary I intake and urinary I output were investigated in an experimental diet study. An exemplary lactovegetarian diet was compared with two non-vegetarian, almost isoenergetic diets in the same subjects. A lactovegetarian diet was chosen instead of a pure vegetarian (vegan) diet to ensure at least a minimum I supply with dairy products.

\section{Subjects and methods}

Six healthy adult volunteers (three females aged 24-25 years and three males aged 31-49 years, no palpable goitre) were selected. Because a repeated-measure design was used in the present study (with each individual being his or her own control) the age difference between the males and females was not expected to have any effect on the results of the dietary manipulations. Along with this, the repeatedmeasure design is a powerful tool to detect, even with a 
small sample size of $n 6$ individuals, moderate changes of about $20 \%$ in biological variables such as adrenal androgens (Remer et al. 1995, 1996a) known to be relatively unresponsive to certain endocrine and dietary treatments (Remer et al. 1995, 1996b).

Mean BMI values were 22.5 (SD 2.3) and 24.4 (SD $2.4) \mathrm{kg} / \mathrm{m}^{2}$ for females and males respectively. The study protocol was approved by the institutional review board of the Dortmund Research Institute of Child Nutrition. All subjects gave written informed consent after the experimental protocol was explained to them in detail.

The initial aim of the present study was to investigate whether it is possible to estimate reliably the renal net acid excretion produced by different natural food diets. The underlying study protocol allowed us also to investigate the dietary impact on individual I status. There was no danger of interfering with the initial study aim after the following additional adjustments for the I issue had been introduced: no fish, no sea food, and no iodized salt at all were ingested during the different experimental diet periods. In addition, the only beverage allowed was an I-free water (Volvic; Puy-De-Dome, France) with a very low mineral content. However, its use was intended per se in order to ensure that the minerals originating from the beverage (which was available ad libitum) did not affect acid-base metabolism. Furthermore, none of the processed foods (bread, cheese etc.) given with the experimental diets was enriched with I or contained iodized salt.

Since the results on diet-dependent renal net acid excretion have already been published along with a detailed description of methods (Remer \& Manz, 1994a), the methods are briefly summarized here.

This investigation, a controlled experimental diet study, was a repeated-measure design and was carried out in four consecutive diet periods during which all subjects received the respective diets in the same chronological order. Each diet period lasted $5 \mathrm{~d}$. In the initial period, a normal $(\mathrm{N})$ moderately protein-rich diet was fed. This was followed by a protein-rich $(\mathrm{P})$ diet, a lactovegetarian $(\mathrm{L})$ diet, and a repetition of the initial diet $\mathrm{N}$. The repeat diet $\mathrm{N}$ was slightly modified in that $20 \mathrm{mmol}(3.0 \mathrm{~g})$ L-methionine (Acimethin, Gry-Pharma, Kirchzarten, Germany) was additionally administered daily specifically to increase renal net acid load.

Protein, carbohydrate, fat, and energy contents of the diets are given in Table 1. A description of the composition of the diets according to major food groups is given in Table 2. The diet periods $\mathrm{P}, \mathrm{L}$, and repeat $\mathrm{N}$ were each separated by a $9 \mathrm{~d}$ interval without dietary restrictions (except for the recommendation to use iodized table salt and to eat I-rich foods). A $2 \mathrm{~d}$ interval without strict diet regulations was set between the initial $(\mathrm{N})$ and the second (P) period.

Dietary intervention periods of $5 \mathrm{~d}$ duration were chosen to clearly identify physiologically relevant short-term (not acute) effects on I metabolism and to assure full dietary compliance. Acute changes in I intake can be observed in $24 \mathrm{~h}$ urine samples within 1-2 d (Wahl et al. 1998), whereas long-term changes in urinary I output with full adaptation of thyroid metabolism takes at least 4 months (Höhler et al. 1990).
Table 1. Macronutrient compositions of the normal ( $\mathrm{N}$; moderately protein-rich), protein-rich $(\mathrm{P})$, and lactovegetarian $(\mathrm{L})$ diets

\begin{tabular}{lrrr}
\hline & \multicolumn{3}{c}{ Diet } \\
\cline { 2 - 4 } & $\mathrm{N}$ & \multicolumn{1}{c}{$\mathrm{P}$} & \multicolumn{1}{c}{$\mathrm{L}$} \\
\hline Energy $(\mathrm{kJ} / 70 \mathrm{~kg} \text { per } \mathrm{d})^{*}$ & 8263 & 8439 & 8171 \\
Fat $(\mathrm{g} / 70 \mathrm{~kg}$ per d) & 73 & 87 & 82 \\
Carbohydrate $(\mathrm{g} / 70 \mathrm{~kg}$ per $\mathrm{d}){ }^{*}$ & 245 & 195 & 267 \\
Protein $(\mathrm{g} / \mathrm{d}) \dagger$ & 95 & 120 & 49 \\
\hline
\end{tabular}

* Additional energy (335-670 kJ) was ingested in individually constant daily amounts during all diet periods as carbohydrates (Dextro Energen (dextrose and maltodextrin); Maizena GmbH, Heilbronn, Germany) according to individual preference.

†The protein content of the diet was kept nearly constant for all subjects receiving the same diet, irrespective of sex and weight.

All foods and meals prepared for the diets were weighed and/or measured precisely and the apportioned meals were completely ingested. Cooking losses of electrolytes and minerals were virtually completely avoided, e.g. by including the total amount of cooking water (used for the preparation of vegetables and potatoes) in the final meals. On one day of each diet period exactly $20 \%$ of each meal was collected (from the respective meals prepared in appropriate excess) and the portions were combined for subsequent homogenization, lyophilization, and I analysis. During the last $2 \mathrm{~d}$ of each diet period, timed $24 \mathrm{~h}$ urine samples were collected and immediately stored at below $-20^{\circ}$. External I contaminations (Neubert \& Remer, 1996) were carefully avoided. Quantification of urinary I was carried out by a modified Sandell-Kolthoff method after wet ashing of the samples (Wawschinek et al. 1985). For each diet four portions of the homogenized and lyophilized total menus were subjected to alkaline ashing before the determination of I by the Sandell-Kolthoff reaction (Aumont \& Tressol, 1986). Single measurements were performed for each of

Table 2. Compositions of the normal ( $\mathrm{N}$; moderately protein-rich), protein-rich $(\mathrm{P})$, and lactovegetarian $(\mathrm{L})$ diets according to major food groups

\begin{tabular}{lccc}
\hline & \multicolumn{3}{c}{ Diet } \\
\cline { 2 - 4 } & $\mathrm{N}$ & $\mathrm{P}$ & $\mathrm{L}$ \\
\hline Meat, meat products $(\mathrm{g} / \mathrm{d})$ & 190 & 220 & 0 \\
1st Breakfast & 50 & - & - \\
2nd Breakfast & 10 & - & - \\
Lunch & 120 & 200 & - \\
Snack & - & - & - \\
Dinner & 10 & 20 & - \\
Cheese and eggs (g/d) & 60 & 340 & 0 \\
1st Breakfast & 20 & 80 & - \\
2nd Breakfast & - & 100 & - \\
Lunch & - & 40 & - \\
Snack & - & 20 & - \\
Dinner & 40 & 100 & - \\
Fruits and vegetables (g/d) & 700 & 230 & 1610 \\
1st Breakfast & - & - & 100 \\
2nd Breakfast & - & 100 & 120 \\
Lunch & 550 & 80 & 680 \\
Snack & 100 & - & 150 \\
Dinner & 50 & 50 & 560 \\
\hline
\end{tabular}


the 'total menu portions' ( $\mathrm{n} 4$ measurements per diet). Twoway ANOVA for repeated measurements and $t$ test for paired observations were applied for statistical evaluation (significance level: $P=0.05$ ). Significance was adjusted for multiple comparisons by the Bonferroni procedure (three two-way comparisons, adjusted significance level: $P=0 \cdot 017)$.

\section{Results}

A clear influence of diet on daily urinary I excretion was observed. Individual I excretion values with the diets are shown in Fig. 1. Renal $24 \mathrm{~h}$ I output was lowest with the lactovegetarian diet and significantly higher with the omnivorous diets $\mathrm{N}$ and $\mathrm{P}$ (Fig. $1 ; F$ value for the factor diet: $12.4, P=0.001$; initial $\operatorname{diet} \mathrm{N} v$. $\operatorname{diet} \mathrm{L}, P=0.01$; $\operatorname{diet} \mathrm{P} v$. $\operatorname{diet} \mathrm{L}, P=0.001)$. Mean daily I excretion with the initial and the repeat diet $\mathrm{N}$ did not differ significantly (Fig. 1; $P=0.51)$ and both diet periods ( $\mathrm{N}$ and repeat $\mathrm{N}$ ) are therefore referred to in the following as diet $\mathrm{N}$ without further differentiation. The average daily urinary I excretion over all experimental diet periods was found to be $50 \cdot 7$ (SD 13.2) $\mu \mathrm{g} / \mathrm{d}$.

In accord with the I excretion data a markedly reduced I intake was confirmed analytically for diet L compared with diets $\mathrm{N}$ and $\mathrm{P}$. With the latter diets the analysed daily I intakes were more than twice as high as the lactovegetarian diet. However, urinary I output clearly exceeded measured I intake with all three diets (Fig. 2). The average difference between measured I intake and measured urinary I excretion ranged from 15.0 to $21 \mu \mathrm{g} / \mathrm{d}$. The I content as estimated from food composition tables (Souci et al. 1994) and the analysed I content were found to be nearly identical for diet

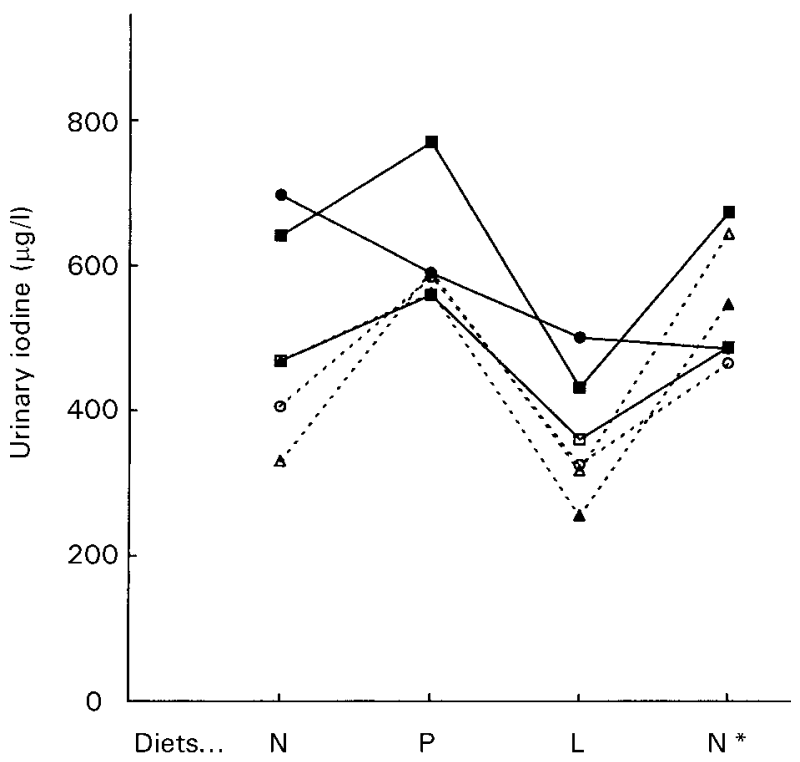

Fig. 1. Individual average $24 \mathrm{~h}$ iodine excretion rates for male $(-)$ and female (- - - ) subjects consuming different diets: normal $(\mathrm{N}$; moderately protein-rich), protein-rich $(\mathrm{P})$, lactovegetarian $(\mathrm{L})$ and $\mathrm{a}$ repeat of the normal diet $\left(\mathrm{N}^{*}\right)$. The average $24 \mathrm{~h}$ iodine excretion was obtained for each subject from the mean urinary output of the two $24 \mathrm{~h}$ specimens collected successively on days 4 and 5 of each diet period. For details of procedures, see p. 46.

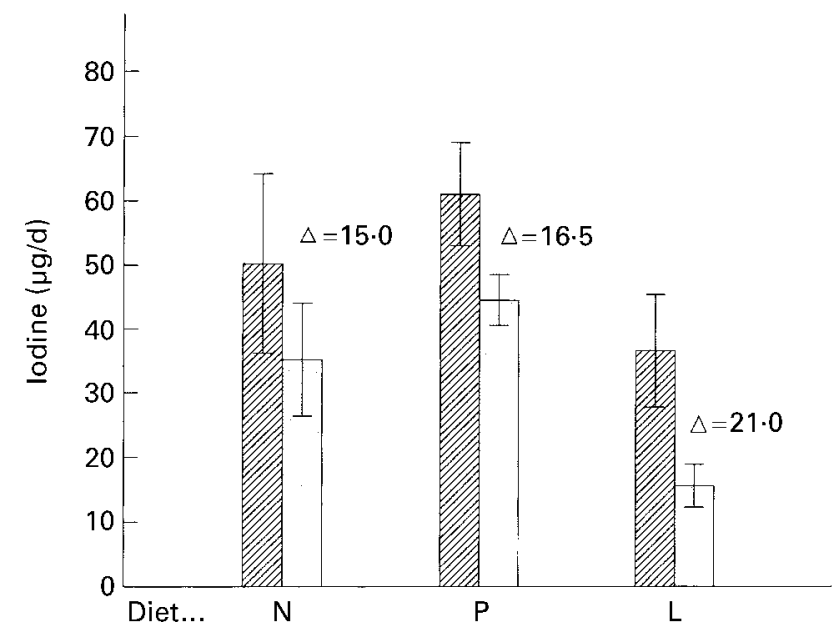

Fig. 2. Comparison of mean analysed iodine intake (圓; from four single measurements of separate representative samples of the total menus) and mean analysed urinary iodine excretion (四) by six subjects consuming different diets: normal $(\mathrm{N}$; moderately proteinrich), protein-rich $(P)$ and lactovegetarian $(L)$. Values are means with standard deviations represented by vertical bars. $(\triangle)$, Difference $(\mu \mathrm{g} / \mathrm{d})$ between mean iodine intake and mean iodine excretion. For details of diets, see Tables 1 and 2 .

$\mathrm{P}$, but for diets $\mathrm{N}$ and $\mathrm{L}$ clearly higher I levels were estimated from food tables than were measured analytically (results not shown).

\section{Discussion}

Indirect evidence of greater deficiency problems with vegetarian diets compared with meat-containing mixed diets might be seen in the fact that I deficiency is usually most prevalent in rural populations (Sullivan et al. 1997) which primarily consume plant foods. However, a low I concentration in the soil of the region affects the I concentrations of both plant and animal products. In industrialized countries I replacement in soil, but not in animal feed, is uncommon. In accord with this are the results of an American diet study in which the foods of typical market basket samples were analysed for their I content. The food groups potatoes, leafy vegetables, legume vegetables, root and miscellaneous vegetables, and fruits contributed only about $10 \mu \mathrm{g} / \mathrm{d}$ to total I intake (Park et al. 1981). These data correspond with the very low I intake $(16 \mu \mathrm{g} / \mathrm{d})$ that was analytically determined for diet L (fruits and vegetables $1610 \mathrm{~g} / \mathrm{d}$ ) of the present study.

The use of food tables for the calculation of I intakes yielded a marked overestimation for diets $\mathrm{N}$ and $\mathrm{L}$, i.e. for diets with high contents of fruits and vegetables. This overestimation of I content in the vegetable and fruit groups seems to be a particular problem related to those food tables (Holland et al. 1991; Souci et al. 1994) which contain I data at a relatively high level (as is appropriate for plants from regions with a high I content in the soil). Recently, Rauma et al. (1994) using regional Finnish food tables, calculated an average daily I intake in vegans of only $29 \mu \mathrm{g} / \mathrm{d}$, whereas Draper et al. (1993) (using British tables) reported a nearly 3-fold higher I intake in vegans. Such discrepancies underline the importance of clearly 
defined, analytically verified (experimental) data on I intake and excretion with different forms of nourishment in order to clarify whether certain vegetarian dietary practices might bear a health risk.

The average I excretion (calculated over all diet periods) was found to be low (i.e. about $50 \mu \mathrm{g} / \mathrm{d}$ ). This low level is only, in part, attributable to the switch from a pre-experimental state of regular consumption of iodized table salt and occasional ingestion of sea fish (and/or sea food) to the experimental situation without consumption of any of these foodstuffs. However, the low average I excretion is primarily caused by the fact that none of the processed foods eaten by the participants with the experimental or the pre-experimental diets were enriched with I or contained iodized salt. This is due to the very restrictive German food legislation on iodization of foods which was in force until recently. In addition to this, the I content of German drinking water is very low (on average $5 \mu \mathrm{g} / \mathrm{l}$; Manz, 1992), and German milk produced during the summer months contains less than $70 \mu \mathrm{g} \mathrm{I} / 1$ as measured in our laboratory in exemplary samples collected in 1997.

The low overall urinary I output in our diet experiment is in accord with the results of large cross-sectional studies performed in Germany during recent years showing that until the mid 1990s Germany has been a classical I-deficient country with average urinary I excretion levels of $70 \mu \mathrm{g} \mathrm{I} / \mathrm{g}$ creatinine in adults (Hampel et al. 1996) and $60 \mu \mathrm{g} / \mathrm{d}$ per $1.73 \mathrm{~m}^{2}$ (standardized to the adult body surface area of $1.73 \mathrm{~m}^{2}$ ) in children (Remer \& Manz, 1994b). Endemic goitre has been scientifically documented for decades and is still present in Germany (Delange et al. 1997; Hampel et al. 1997).

In the present diet experiment with its temporary cessation of sea fish and iodized salt consumption, a metabolic steady state (with a quantitatively balanced I intake and excretion) could not be achieved within each of the four experimental periods. This is clearly reflected in $24 \mathrm{~h} \mathrm{I}$ excretion values exceeding the analysed daily I intake in all dietary periods. Obviously, during none of the short-term diet periods could absolute thyroid I uptake increase appropriately to compensate for the experimentally reduced I intake. Consequently thyroid I losses must have contributed to $24 \mathrm{~h}$ urinary I excretion and the actual dietary I deficit was more severe than reflected by urinary excretion data alone.

The measured average I intakes of 35 and $45 \mu \mathrm{g} / \mathrm{d}$ with diets $\mathrm{N}$ and $\mathrm{P}$ respectively, fell below the biological minimum requirements of healthy adults assumed to range between 50 and $80 \mu \mathrm{g} / \mathrm{d}$ (Meng, 1992). These findings again confirm that dietary practices which specifically exclude the use of iodized table salt and the consumption of fish, sea food, and processed I-enriched foods, put great pressure on thyroidal management of I balance. However, this pressure further increases if, apart from the previously mentioned foodstuffs, meat and meat products are also avoided (diet $\mathrm{L}$, measured I intake $<20 \mu \mathrm{g} / \mathrm{d}$ ). Among the various vegetarian regimens, followers of vegan and total vegetarian diets frequently adopt dietary practices which are comparable to the nutritional situation with diet L (except for the consumption of dairy products with the latter). Vegans (or total vegetarians) not only reject all animal products and processed foods but often reject iodized salt as a processed product as well. Sea salt (containing virtually no I) is used as a 'natural product' instead.

Our results experimentally confirm literature findings (primarily based on food table-derived estimates) indicating that I supply is higher with non-vegetarian than with vegetarian diets. Specifically, the extremely low intake and urinary output of I as analytically determined for diet L, clearly demonstrate how unacceptably limiting the I supply can become when stricter forms of vegetarian dietary practices are followed. As long as alternative methods of I supplementation based on I replacement in soil are used only sporadically (Cao et al. 1994; DeLong et al. 1997) the I contents of fruits and vegetables will remain extremely low in most regions worldwide. Nutritionists and physicians should consider that strict vegetarians are possibly at risk of developing I deficiency disorders especially if anamnesis reveals that neither iodized salt nor iodine supplements (including seaweed preparations) are taken. In a group of North American total vegetarians who used only uniodized sea salt, significantly reduced serum I concentrations and clearly elevated thyroid stimulating hormone levels were detected with a prevalence of $25 \%$, and $12 \%$ of the total group developed hypothyroidism (Crane et al. 1992). Further studies specifically investigating biochemical and clinical indicators of I status in strict vegetarians appear to be necessary.

\section{Acknowledgements}

This work has been supported by the Ministerium für Wissenschaft und Forschung des Landes NordrheinWestfalen and the Bundesministerium für Gesundheit.

\section{References}

Aumont G \& Tressol J-C (1986) Improved routine method for the determination of total iodine in urine and milk. Analyst 111, $841-843$.

Cao X-Y, Jiang X-M, Kareem A, Dou Z-H, Rakeman MA, Zhang M-L, Ma T, O’Donnell K, DeLong N \& Delong GR (1994) Iodination of irrigation water as a method of supplying iodine to a severely iodine-deficient population in Xinjiang, China. Lancet 344, 107-110.

Cobra C, Muhilal, Rusmil K, Rustama D, Djatnika, Suwardi SS, Permaesih D, Muherdiyantiningsih, Martuti S \& Semba RD (1997) Infant survival is improved by oral iodine supplementation. Journal of Nutrition 127, 574-578.

Crane MG, Mullen T \& Lukens R (1992) Iodine status of total vegetarians. Proceedings of the Second International Congress on Vegetarian Nutrition held in Arlington, Virginia, 1992. p. 15, Abstr.

Delange F (1994) The disorders induced by iodine deficiency. Thyroid 4, 107-128.

Delange F, Benker G, Caron Ph, Eber O, Peter F, Podoba J, Simescu M, Szybinsky Z, Vertongen F, Vitti P, Wiersinga W \& Zamravil V (1997) Thyroid volume and urinary iodine in European schoolchildren: standardization of values for the assessment of iodine deficiency. European Journal of Endocrinology 136, 180-187.

DeLong GR, Leslie PW, Wang S-H, Jiang X-M, Zhang M-L, Rakeman MA, Jiang J-Y, Ma T \& Cao X-Y (1997) Effect on infant mortality of iodination of irrigation water in a severely iodine-deficient area of China. Lancet 350, 771-773. 
Draper A, Lewis J, Malhotra N \& Wheeler E (1993) The energy and nutrient intakes of different types of vegetarian: a case for supplements? British Journal of Nutrition 69, 3-19.

Hampel R, Gordalla A, Zöllner H, Klinke D \& Demuth M (1997) Alimentäre Jodzufuhr bei Jugendlichen in MecklenburgVorpommern zwischen 1993 und 1996 gestiegen (Iodine intake of adolescents in Mecklenburg-Vorpommern increased between 1993 and 1996). Zeitschrift für Ernährungswissenschaft 36, 151-154.

Hampel $\mathrm{R}$ Kühlberg $\mathrm{T}$, Zöllner $\mathrm{H}$, Klinke $\mathrm{D}$, Klein $\mathrm{K}$, Pichmann E-G \& Kramer A (1996) Aktueller Stand der alimentären Jodversorgung in Deutschland (Current iodine status in Germany). Zeitschrift für Ernährungswissenschaft 35, 2-5.

Höhler M, Tölle H-G \& Manz F (1990) Seefischverzehr und Jodversorgung (Sea fish consumption and iodine status). Aktuelle Ernährungs-Medizin 15, 187-193.

Holland B, Welch AA, Unwin ID, Buss DH, Paul AA \& Southgate DAT (1991) McCance and Widdowson's The Composition of Foods, 5th ed. Cambridge: The Royal Society of Chemistry/ Ministry of Agriculture, Fisheries and Food.

International Council for Control of Iodine Deficiency Disorders (1997) Africa struggles for independence from IDD. Report of the 1996 Harare Conference. IDD Newsletter 13, no. 2, 17-30.

Lightowler HJ \& Davies GJ (1996) Sources of iodine in the vegan diet. Proceedings of the Nutrition Society 55, 13A.

Maberly GF, Trowbridge FL, Yip R, Sullivan KM \& West CE (1994) Programs against micronutrient malnutrition: ending hidden hunger. Annual Review of Public Health 15, 277-301.

Manz F (1992) Jodmangel. Gründe, Folgen und Vorbeugungsmaßnahmen (Iodine deficiency. Reasons, consequences, and preventive measures). Prävention 15, 111-117.

Meng W (1992) Anatomie und Physiologie (Anatomy and physiology). In Schilddrüsenkrankheiten: Pathyphysiologie, Diagnostik und Therapie (Diseases of the Thyroid: Pathophysiology, Diagnostic Investigation and Therapy), pp. 18-39 [W Meng, editor]. Stuttgart: Gustav Fischer Verlag.

Neubert A \& Remer T (1996) Measurement of urinary iodine concentration (letter). Lancet 347, 1414-1415.

Park YK, Harland BF, Vanderveen JE, Shank FR \& Prosky L
(1981) Estimation of dietary iodine intake of Americans in recent years. Journal of the American Dietetic Association 79, $17-24$.

Rauma A-L, Törmälä M-L, Nenonen M \& Hänninen O (1994) Iodine status in vegans consuming a living food diet. Nutrition Research 14, 1789-1795.

Remer T \& Manz F (1994a) Estimation of the renal net acid excretion by adults consuming diets containing variable amounts of protein. American Journal of Clinical Nutrition 59, 1356-1361.

Remer T \& Manz F (1994b) The inadequacy of the urinary iodinecreatinine ratio for the assessment of iodine status during infancy, childhood, and adolescence. Journal of Trace Elements and Electrolytes in Health and Disease 8, 217-219.

Remer T, Manz F \& Pietrzik K (1995) Re-examination of the effect of hCG on plasma levels and renal excretion of dehydroepiandrosterone sulfate in healthy males. Steroids 60, 204-209.

Remer T, Pietrzik K \& Manz F (1996a) The short-term effect of dietary pectin on plasma levels and renal excretion of dehydroepiandrosterone sulfate. Zeitschrift für Ernährungswissenschaft 35, 32-38.

Remer T, Pietrzik K \& Manz F (1996b) A moderate increase in daily protein intake causing an enhanced endogenous insulin secretion does not alter circulating levels or urinary excretion of dehydroepiandrosterone sulfate. Metabolism 45, 1483-1486.

Souci SW, Fachmann W \& Kraut H (1994) Food Composition and Nutrition Tables, 5th ed. Stuttgart: Medpharm Scientific Publishers.

Sullivan KM, May W, Nordenberg D, Houston R \& Maberly GF (1997) Use of thyroid stimulating hormone testing in newborns to identify iodine deficiency. Journal of Nutrition 127, 55-58.

Wahl R, Breidt M \& Kallee E (1998) Iodide supplementation: $200 \mu \mathrm{g}$ daily or $1500 \mu \mathrm{g}$ weekly? Zeitschrift für Ernährungswissenschaft 37, 18-21.

Wawschinek O, Eber O, Petek W, Wakonig P \& Gürakar A (1985) Bestimmung der Harnjodausscheidung mittels einer modifizierten Cer-Arsenitmethode (Determination of urinary iodine excretion using a modified cer-arsenite method). Berichte $\ddot{O} G K C$ 8, 13-15. 